ISSN 1112-9867

Available online at $\quad$ http://www.jfas.info

\title{
RELATIONSHIP BETWEEN LEADERSHIP STYLE AND PERFORMANCE OF PERAK SUKMA ATHLETES AND COACHES
}

\author{
H. K. Chee*, N. M. Rasyid, R. Y. Tengah, J. F. L. Low \\ Faculty of Sports Science and Coaching, Universiti Pendidikan Sultan Idris, Tg Malim, Perak, \\ Malaysia.
}

Published online: 10 November 2017

\begin{abstract}
The purpose of this study was to examine the relationship between leadership style and performance of athletes and coaches in Malaysia. One hundred and thirty seven athletes and 47 coaches from 12 sports participated in the study. Leadership Scale for Sport (LSS) questionnaire was utilized to assessed athletes' preference, perceived and coaches' perception of their own leadership style. Result showed athletes most preferred coaching styles were training and instruction followed by democratic, positive feedback and social support. Autocratic behaviour was the least preferred. However coaches' self-evaluation showed majority were keen on autocratic leadership style. Overall, the results of the study proposed that coaches should emphasis on training and instruction and less autocratic leadership style. Coaches also need to practise more positive feedback which proven can enhance athletes performance.
\end{abstract}

Key word: Leadership style, sports performance, coach, athletes.

Author Correspondence, e-mail: nelfianty@fsskj.upsi.edu.my

doi: http://dx.doi.org/10.4314/jfas.v9i6s.97 


\section{INTRODUCTION}

Leadership is generally defined as the behavioral process of influencing the activities of organized individuals and group toward specific goals and the achievement of those goals [1]. Coaches who are able to adapt their leadership qualities according to athlete's preferences can promote a pleasant and optimizing a good learning environment. Most coaches failed to consider the needs of their players. A positive relationship in between coaches and athletes has been widely recognized as an intermediary to drive for success and satisfaction in sports settings [2]. Coaching behaviours preferred by athletes may lead to increased satisfaction and performance of the players. Therefore, coaches must pay attention to each of their athletes to help and motivate them in learning the skills and improve performance. Leadership style is a sophisticated social process in which coaches need to be an effective communicator because they wield influence to the athletes and the view of the society [3]. Leadership in sports not

only involves governing sports associations or managerial duties but, more importantly the role of the coaches who are directly responsible with the athletes.

Coaching leadership style is important while giving guidance or training to the athletes. In 1967, in [4] contingency model, proposed that the style of a leader is an outcome of leaders' required and individuality. It is necessary for the coach to first assess the situation itself before the leader's style can be matched to a certain situation. In the path-goal theory, the leader is viewed as a facilitator who helps subordinates achieve their goals [5]. Leadership is a process to optimize the subordinates' performance and attain their goals.

Previous research in sport psychology suggested that coaching is important leadership ability and effects on an athlete's attitudes and performances [6 - 7]. In any sports competition, athletes would strive for better performance in order to achieve success. During the training sessions, coaches are required to make good use of information and feedback from the athletes and apply them into the training routine. In order to achieve the goals and objectives of the athletes, coaches need to identify appropriate leadership style to the team or their athletes. Furthermore, coaches understanding of their own leadership style can be more proactive and effective by strategically using their strengths and counteracting their weaker areas. This research aimed to determine the leadership styles of coaches and their relationship with the performance of their athletes. This study also examined whether there was 
congruence in required and preferred leadership styles by the athletes.

In the current coaching aspect, gender plays an important role $[2,8]$. Increasing the number of female participated in athletics and coaching positions will create more cross gender coach-athlete relationship. This study attempted to compare male and female athletes' preferences and perceived on coaching leadership behaviors and coach self-evaluation as measured by Leadership Scale for Sports (LSS). This study also explored the relationship between leadership preference and performance outcome in the Malaysian Games (SUKMA), held in Kuching, Sarawak in 2016. The following research questions were specifically formed for this study:

1. What were the athlete's preference coaching leadership styles?

2. Did the coach leadership styles preferred by athletes differ based on gender?

3. What were the athlete's perceptions to their coach?

4. What were the coaches' perceptions of their own coaching behaviours?

5. Was there a relationship between the athlete's perceiving coaching leadership styles with their performances?

\section{METHOD}

\subsection{Participants}

A total of 137 athletes (male, $\mathrm{n}=76$; female, $n=61$ ), ages ranging from 12 to 20 years of age $(M=16.58, S D=1.9)$ and 47 coaches (male, $\mathrm{n}=39$; female, $\mathrm{n}=8)$ participated in this study. They were involved in the 2016 SUKMA Games which was held in Sarawak. Athletes from 12 sports were recruited in this study (cycling, $n=2$; boxing, $n=3$; bowling, $n=11$; weight lifting, $\mathrm{n}=9$; lawn ball, $\mathrm{n}=9$; silat, $\mathrm{n}=17$; track and field, $\mathrm{n}=12$; taekwondo, $\mathrm{n}=16$; karate-do, $\mathrm{n}=18$; archery, $\mathrm{n}=7$; wushu, $\mathrm{n}=12$; and shooting, $\mathrm{n}=21$ ).

\subsection{Instruments}

The Leadership Scale for Sports questionnaire (LSS) by [9] was adapted to obtain (a) athletes' preferences for specific coaching leadership styles, (b) athletes' perceptions of their coach's leadership styles, and (c) coaches' perception of their own leadership styles. For the preference version, the items were preceded by ("I prefer my coach to ....") and for the perceived version, the items were preceded by ("My coach. . ."), meanwhile for coach 
self-evaluation version, the items were preceded by (“I...").

The LSS questionnaire contained 40 items that assessed five dimensions of leadership styles: training and instruction (13 items), democratic (9 items), autocratic (5 items), social support (9 items), and positive feedback (5 items). Athletes will respond to each item using a 5-point Likert scale containing the following selections: 1=Always, 2=Often, 3=Occasionally, 4=Seldom, 5=Never. Previous research has shown the LSS to be valid and reliable instruments [9-11]. The Malay version of LSS used in this study has been reported its reliability coefficients ranging from 0.59 to 0.91 [12].

Performance outcomes for this study were obtained from public domain data available from the SUKMA Sarawak 2016 website and Majlis Sukan Negeri (MSN) Perak. The authors categorized the specific performance scale for each athletes on a 5-point scale ranging from 1

$\left(1^{\text {st }}\right.$ round), 2 ( $2^{\text {nd }}$ round), 3 (Quarterfinal), 4 (Semi-finals) to 5 (Final) in terms of results of performance in the Games.

\subsection{Data Analysis}

Results were analysed using Statistical Package for Social Science (SPSS) version 20. Means and standard deviations for the demographic variables were reported along with the LSS scores. Inferential statistics, such as independent sample t-test were used to identify differences in the dimensions of coach leadership style based on gender. Multiple regression were used to analyse relationship between the athlete's perceived coaching leadership styles with the SUKMA 2016 performances. The alpha level required for significance for all tests was set at $p<.05$.

\section{RESULTS}

\subsection{Athletes Preferred Leadership Style}

Based on the scale of 1 (always) to 5 (never) from the LSS, the results in Table 1 showed that athletes' most preferred leadership style was training and instruction, followed by democratic, positive feedback and social support. Autocratic leadership style was the least preferred coaching behavior. 
Table 1. Leadership Style Preferred by the Perak SUKMA athletes.

Values were expressed as Mean $\pm \mathrm{SD}$.

\begin{tabular}{lccc}
\hline Coaching Dimension & $n$ & & $S D$ \\
& \multicolumn{2}{c}{$M$} \\
\hline Training and instruction & 137 & 2.11 & 0.81 \\
Democratic & 137 & 2.17 & 0.72 \\
Positive feedback & 137 & 2.33 & 0.86 \\
Social support & 137 & 2.40 & 0.81 \\
Autocratic & 137 & 3.74 & 0.92 \\
\hline
\end{tabular}

\subsection{Coaching Preferences Leadership Style Based on Athletes' Gender}

Separate independent samples t-tests was conducted to compare mean score of the preferences leadership style based on the gender of SUKMA Perak athletes. Result was depicted in Table 2.

Table 2. Independent Samples t-test on Leadership Styles preferences

\begin{tabular}{lccccccc}
\hline \multicolumn{1}{c}{ Coaching Dimension } & Gender & $n$ & $M$ & $S D$ & $t$ & $d f$ & Sig.(2-tailed) \\
\hline Autocratic & Male & 76 & 3.76 & 0.90 & 0.367 & 135 & 0.71 \\
& Female & 61 & 3.70 & 0.95 & & & \\
Positive feedback & Male & 76 & 2.47 & 0.88 & 2.19 & 135 & $0.03^{*}$ \\
& Female & 61 & 2.15 & 0.81 & & & \\
Social support & Male & 76 & 2.52 & 0.84 & 1.92 & 135 & $0.05^{*}$ \\
& Female & 61 & 2.25 & 0.76 & & & \\
Democratic & Male & 76 & 2.22 & 0.74 & 1.06 & 135 & 0.29 \\
& Female & 61 & 2.09 & 0.69 & & & \multirow{2}{*}{$0.04^{*}$} \\
Training and instruction & Male & 76 & 2.23 & 0.83 & 2.01 & 135 & \\
& Female & 61 & 1.95 & 0.74 & & & \\
\hline
\end{tabular}

* Significant level $p<.05$.

Independent samples t-tests showed that there were significant different between preferences leadership style based on gender. The female athletes preferred more positive feedback, $\mathrm{t}(135)$ $=2.19, p<.05$; social support $\mathrm{t}(135)=1.92, p<.05$; training and instruction $\mathrm{t}(135)=2.01, p$ $<.05$ than male athletes.

\subsection{Perak State SUKMA Athletes Perception of their Coach's Leadership Styles}

The result indicated that Perak state SUKMA athletes' most perceived autocratic $(\mathrm{M}=2.46$, $\mathrm{SD}=0.83)$ leadership style followed by social support $(\mathrm{M}=3.28, \mathrm{SD}=0.68)$, positive 
feedback $(\mathrm{M}=3.29, \mathrm{SD}=0.81)$, training and instruction $(\mathrm{M}=3.37, \mathrm{SD}=0.72)$, and democratic behavior $(\mathrm{M}=3.55, \mathrm{SD}=0.76)$.

Table 3. Descriptive statistic for the athlete's perception of coach's leadership style Values were express as Mean $\pm \mathrm{SD}$.

\begin{tabular}{lccr}
\hline Variable & $n$ & $M$ & $S D$ \\
\hline Autocratic & 137 & 2.46 & 0.83 \\
Social support & 137 & 3.28 & 0.68 \\
Positive feedback & 137 & 3.29 & 0.81 \\
Training and instruction & 137 & 3.37 & 0.72 \\
Democratic & 137 & 3.55 & 0.76 \\
\hline
\end{tabular}

\subsection{Analysis the SUKMA Perak State Coaches' Perception of their own Leadership Styles}

Table 4 showed that the SUKMA Perak head coaches' perception of their own coaching behavior were more on autocratic coaching behavior and followed by democratic, social support, positive feedback and lastly was training and instruction behavior. This finding was congruence with athletes perception where majority of the athletes' perceived most of their coach used autocratic leadership style.

Table 4. Coaches' self-evaluation on their own leadership style Values are expressed as Mean $\pm \mathrm{SD}$.

\begin{tabular}{lllr}
\hline Leadership Styles & $n$ & $M$ & $S D$ \\
\hline Autocratic & 47 & 2.20 & 0.57 \\
Democratic & 47 & 3.70 & 0.58 \\
Social Support & 47 & 4.24 & 0.86 \\
Positive feedback & 47 & 4.32 & 0.49 \\
Training and Instruction & 47 & 4.45 & 0.48 \\
\hline
\end{tabular}

3.5 Relationship between Athletes' Perceiving Coaching Leadership Styles with SUKMA 2016 Performance Outcome.

Multiple regression analysis was used to test if the leadership styles significantly predicted 
performance in SUKMA Games 2016. The results of the regression indicated positive feedback explain $4.5 \%$ of the performance $(\mathrm{R} 2=0.045, \mathrm{~F}(5,140)=6.355, p<0.05)$. It was found that positive feedback leadership style significantly predicted performance outcomes ( $\beta$ $=-0.212, p<0.05)$. In this case, the negative correlation meant higher of positive feedback behavior enhanced athlete performance because of the LSS scoring and performance scale used in this present study. The results of the analysis were presented in Table 5.

Table 5. Model summary of multiple regressions

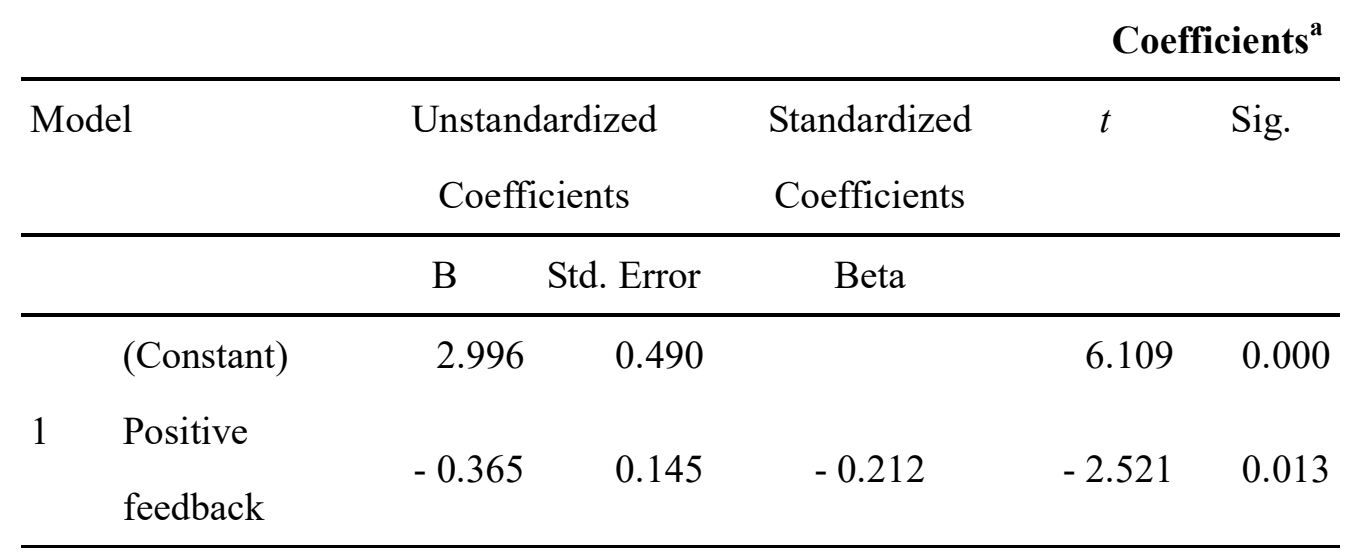

a. Dependent Variable: performance

\section{DISCUSSION}

The findings of this research indicated that training and instruction was the most preferred coaching leadership style followed by democratic, positive feedback, social support. Autocratic leadership style was the least preferred coaching behavior. This research finding supported previous studies [13-15], which found that training and instruction coaching behaviour was the most preferred leadership style. According to [9], training and instruction behaviour is aimed at improving performance. Therefore, coaches should structure the technique and tactics of the sport to train the athletes. Training and instruction leadership style relate to task orientated skill development and would appear to have been identified by the elite players as essential coaching behaviour to enhance their performance and subsequence likelihood of success [16]. 
This study revealed that female athletes preferred training and instruction, social support and positive feedback leadership styles more than their male counterpart. Findings supported previous studies that males and female athletes preferred different coaching behaviours [17-18, $14,2]$. The findings suggested that coaches should use different coaching styles for male and female athletes.

The third research question was to examine the athlete's perception of their coaches' leadership style. Athlete's perceived leadership style helped coaches to understand their perception and it could help them to improve athletes' performance. The results of the present study demonstrated athletes' most perceived leadership behaviour was autocratic. Autocratic coaching behaviour assumes coaches are keen on centralized decision-making and lack of empathy to the athletes [19]. According to multidimensional model of leadership in order to maximize performance and satisfaction there should be congruence between the actual coaching behaviour and preferred behaviour.

Based on the results it shows that the Perak athletes didn't perceive an appropriate coaching leadership style. Athletes preferred more training and instruction leadership style but they perceived more autocratic style from their coaches. In particular, the results of the current study were similar to the findings of previous research $[16,12]$ which majority of athletes did not favour the autocratic leadership style. As according to [17], coach with an autocratic style makes decisions independently and stresses personal authority in working with the decisions. Autocratic coaches were less likely to provide an explanation of their actions to their athletes. Input from athlete is generally not invited by the coaches and athletes dislike this environment.

The following research question was conducted to examine the coaches own perception on their leadership style. Based on the finding it indicated coaches' perception of their own coaching behaviour were inclined to autocratic coaching behaviour. The coaches did not place much emphasis on the training and instruction style of leadership. Instead they were more focus on the autocratic and social support leadership style. Again, this did not correlate positively with the athlete's preference. According to [6], athletes capable of enhance a higher level of personal achievements, performance goals and positive psychological outcome when coaches reinforce effective coaching behaviours toward the needs of athletes. However, the 
current research findings showed the evident these leadership styles practised by the coaches might not develop a strong and solid fundamental movement patterns and skills necessary to improving athlete's performance.

The last objective of this study was to determine relationship between the athletes' perceiving coaching leadership styles with their performance outcome. Leadership style is an important factor which affects the performance of a person or a group of people [20]. Coaches who have the ability to aligning specific strategies and coaching behaviour could extent beliefs among athletes and affect their performance. Multiple regression analysis revealed that positive feedback leadership style will improved the athletes' performances in SUKMA Games. This research findings supported previous research by [16], which showed positive feedback were associated with higher levels of sport performance whereas autocratic leadership style caused a lower levels of performance. Coaches with positive feedback consistently praise or rewards athletes for good performance. According to [17], positive feedback is contingent on the performance and is limited to the athletics contact.

\section{CONCLUSIONS}

This study investigated the preferred and perceived coaching behaviors reported by the SUKMA Perak state athletes based on their gender and the coaches' perception of their own coaching behaviors. This research also explored the relationship between perceived leadership style and performance outcome in SUKMA Games 2016. In conclusion this study finding showed that the Perak athletes' preferred most training and instruction leadership style and least preferred was autocratic behavior. This study also indicated that male and female athletes have differences in preferred leadership style. Female preferred more positive feedback, social support and training and instruction than male athletes. There is no congruency between perceived and preferred leadership style. The coaches were found to practice more autocratic behavior which was the least preferred by athletes. Subsequent findings showed that positive feedback leadership style enhanced the athletes' performance. It is recommended that coaches practice more positive feedback and training and instruction coaching behavior to achieve the best performance for the team.

There were several limitations that must be addressed with respect to this study. The study 
only explored the individual sports. Future study should compare the individual and team sport athletes. This would help coaches to understand the different needs from each group.

\section{ACKNOWLEDGEMENT}

The authors wish to thank the Perak SUKMA athletes, official and all members of Faculty of Sports Science and Coaching, UPSI for their support. The authors acknowledge the athletes and coaches who participated in the study.

\section{REFERENCES}

[1] Northouse, P. G. (2010). Leadership: Theory and practice (5th Ed.). Thousand Oaks, CA: Sage.

[2] Kalin, J. L., \& Waldron, J. J. (2015). Preferences toward gender of coach and perceptions of roles of basketball coaches. International Journal of Exercise Science, 8(4), 1.

[3] Eberly, M., Johnson, M.D., Hernandez, M., \& Avolio, B. (2013). Toward a metatheory of leadership: Conceptualizing the loci and mechanisms of leadership within a multilevel process model. American Psychologist, 68, 427-443.

[4] Fiedler, F. (1967). A theory of leadership effectiveness. New York: McGraw-Hill.

[5] House, R. J. (1971). A path goal theory of leader effectiveness. Administrative Science Quarterly, 321-339.

[6] Horn, T. (2002). Coaching effectiveness in the sport domain. In T. Horn (Ed.), Advances in sport psychology, (2nd ed., pp. 309-354). Champaign, IL. Human Kinetics.

[7] Sullivan, P., Paquette, K., Holt, N., \& Bloom, G. (2012). The relation of coaching context and coach education to coaching efficacy and perceived leadership behaviors in youth sport. Sport Psychologist, 26 (1), 122.

[8] Shrivastava, Y., \& Sharma, R. (2015). A study of leadership behaviour psychological characteristic male and female basketball players in Chhattisgarh state. International Journal of Recent in Social Science and Humanities, 2, 104 - 107.

[9] Chelladurai, P., \& Saleh, S.D. (1980). Preferred leadership in sports. Canadian Journal of Applied Sports Sciences, 3, 85-92.

[10] Chelladurai, P., \& Riemer, H. A. (1998). Development of the athlete satisfaction 
questionnaire (ASQ). Journal of Sport and Exercise Psychology, 20(2), 127-156.

[11] Loughead, T. M., \& Hardy, J. (2005). An examination of coach and peer leader behaviors in sport. Psychology of Sport and Exercise, 6(3), 303-312.

[12] Nelfianty Mohd Rasyid. (2009). Motif Penglibatan, Orientasi Matlamat dan Gaya Kepimpinan Jurulatih Dari Perspektif Atlet Sekolah Sukan Malaysia. Doctoral Dissertation, Universiti Pendidikan Sultan Idris Tg Malim Perak.

[13] Nazarudin, B. H. N. M., Fauzee, O. S. M., Jamalis, M., Geok, K. S., \& Din, A. (2009). Coaching leadership styles and athlete satisfaction among Malaysian University Basketball team. Research Journal of International Studies, 9(1), 4 -11.

[14] Sharma, R. (2015). Preferred leadership behaviours of male and female badminton players. International Journal of Science Culture and Sport, 3(2), 73-83.

[15] Rajabi, Z. (2012). Relationship of coach's leadership style and player performance outcomes. European Journal of Experimental Biology, 2(4), 1134-1136.

[16] Høigaard, R., Jones, G., \& Peters, D. (2008). Preferred coach leadership behaviour in elite soccer in relation to success and failure. International Journal of Sports Science and Coaching, 3(2), 241-250.

[17] Weinberg, R. S., \& Gould, D. (2015). Foundations of sport and exercise psychology. 6th Ed. Champaign, IL: Human Kinetics

[18] Beam, J. W., Serwatka, T.S., \& Wilson, W.J. (2004). Preferred leadership of NCAA division I and II intercollegiate student-athletes. Journal of Sport Behavior, 27(1), 1-17.

[19] Lyle, J. (2005). Sports coaching concepts. A framework for coaches' behaviour. London: Routledge.

[20] Vincer, D. J. E., \& Loughead, T. M. (2010). The relationship between athlete leader behaviours and cohesion in team sports. The Sport Psychologist, 24, 448-467.

\section{How to cite this article:}

Chee H. K., Mohd Rasyid N., Tengah R. Y., Low, J. F. L. Relationship between leadership style and performance of Perak Sukma athletes and coaches. J. Fundam. Appl. Sci., 2017, 9(6S), 1323-1333. 